\title{
Hotelaria diferenciada em capitais do nordeste do Brasil para tripulantes de uma companhia aérea
}

\author{
Erivandeson da Silva Freitas* Julio Cesar Ferreira Lima** \\ Susana Dantas Coelho**** \\ Instituto Federal de Educação, Ciência e Tecnologia do Ceará (Brasil)
}

\begin{abstract}
Resumo: Devido ao crescimento do setor de aviação e à busca da qualidade pela indústria hoteleira, esse estudo destaca o posicionamento de tripulantes de uma companhia aérea brasileira no que diz respeito aos serviços diferenciados que devem ser dispostos a eles. O objetivo geral desse estudo foi demonstrar o nível da qualidade nos serviços hoteleiros de capitais do nordeste do Brasil oferecidos a uma companhia aérea. Foi necessário, pois, levantar o cumprimento das normas de hospedagem estabelecidas pelos órgãos reguladores da aviação; apontar serviços diferenciados oferecidos por hotéis aos tripulantes; e investigar o nível de satisfação dos serviços voltados aos mesmos. O trabalho caracteriza-se como um estudo de caso exploratório, através de pesquisa bibliográfica e de campo, apresentando um questionário como instrumento de pesquisa. A análise dos resultados demonstrou que os hotéis pesquisados cumprem com as normas reguladoras estabelecidas, satisfazendo a maioria dos respondentes; embora melhorias tenham sido apontadas.
\end{abstract}

Palavras-chave: Aviação; Hotelaria; Qualidade; Tripulantes; Região Nordeste.

\section{Distinguished hospitality in northeastern capitals of Brazil for the crew members of an airline}

Abstract: Due to the growth of the aviation sector parallel to the pursuit of quality by the hotel industry, this study highlights the positioning of crew members of a Brazilian airline regarding the different services provided for them. The main objective of this study was to demonstrate the quality of the hotel services offered to a specific airline vy some Brazilian northeast capitals. There was a requirement to raise the standards of hosting set by regulatory aviation bodies; to point out differentiated services offered by hotels to the crew members; and to gauge the level of satisfaction with these services. This work is an exploratory case study wotrking with the literature and through fieldwork, with a questionnaire as the research tool. The results showed that the researched hotels follow the established regulatory standards, satisfying the majority of the crew members; although areas of improvement have been identified.

Keywords: Aviation; Hospitality; Quality; Crew Members; Northeastern Region.

\section{Introdução}

A hotelaria brasileira experimentou diversas transformações desde o primeiro contato entre a tradição indígena e a tradição portuguesa na época do descobrimento do Brasil ${ }^{1}$. Passando pela influência da vinda da família real e fixação da corte portuguesa no país, chega-se a segunda metade do século XIX e ao que pode ser considerado o início do desenvolvimento da hotelaria local. As cidades de São Paulo e do Rio de Janeiro foram as principais representantes desse setor, devido à instalação de hotéis com padrões estabelecidos internacionalmente.

* Tecnólogo em Hotelaria formado pelo IFCE com experiência no setor da aviação; E-mail: erivandeson10@hotmail.com

** Departamento de Turismo y Hospitalidad de IFCE como profesor de inglês (desde 1999) y coordinador administrativo (desde 2008) de los cursos del departamento; E-mail: julioepedrita@gmail.com

*** Doutoranda em Geografia pela Universidade Federal do Ceará (UFC), Mestre em Turismo pela Universidade Estadual do Ceará (UECE) e Bacharela em Turismo pela Faculdade Evolutivo (FACE). Atualmente é professora dos cursos de Turismo e Hospitalidade e coordenadora de courso de Bacharelado em Turismo do IFCE; E-mail: susan.dantas09@gmail.com 
O crescimento da hotelaria brasileira adveio diretamente do incremento do turismo através de viagens em busca de cultura e de lazer, da evolução dos meios de transporte e das melhorias da malha viária urbana, nada muito diferente do que ocorreu no restante do planeta. No início do século XIX, o turismo começa a se firmar no cenário econômico brasileiro com fatos marcantes como a aprovação de uma lei sobre isenção de impostos a grandes hotéis instalados no Rio de Janeiro, então capital federal, o direito a férias remuneradas aos trabalhadores e a chegada do primeiro grupo organizado de turistas ao Rio de Janeiro a bordo do vapor Byron. Consequentemente, a hotelaria passou também por transformações evolutivas no mesmo período. Como marco inicial da hotelaria brasileira moderna, encontravam-se no Rio de Janeiro os hotéis Avenida (1908), até então o maior hotel do Brasil com 220 apartamentos, e o mais luxuoso hotel do país, o Copacabana Palace (1923), com 233 apartamentos. Em São Paulo, entre outros hotéis de destaque, estavam o Hotel Terminus e o Hotel Esplanada, ambos com mais de 200 apartamentos e construídos na década de 1920 (Bosisio, 2005).

De acordo com Silva e Miyashiro (2007: 21), "o turismo tem se caracterizado como uma das atividades capazes de impulsionar o crescimento econômico, dada a capacidade de geração de empregos e divisas." Vários fatores de incremento do turismo fazem a hotelaria passar também por avanços significativos. Não há mais condição de dissociação de ambos os termos. Como afirma Freitas e Silva (2011: 92):

Como segmento integrante e indispensável da cadeia produtiva do turismo, os meios de hospedagem tornam-se estruturas singulares para a formação do conceito de turismo, considerando-se que esta atividade se desenvolve no espaço e que os elementos de transporte, hospedagem e alimentação formam os serviços mínimos, para que o turismo possa existir.

A Organização Mundial do Turismo (OMT) assegura que o turismo se tornou, principalmente nas últimas seis décadas, um dos maiores setores econômicos e de crescimento do mundo. Segundo documento produzido em 2014 sobre o panorama do turismo mundial, uma em cada onze pessoas está empregada na área do turismo. Essa cifra consegue uma representação expressiva de 9\% do PIB do planeta (OMT, 2014).

O crescimento da hotelaria e do turismo também foi relatado no estudo elaborado pelo Fórum de Operadores Hoteleiros do Brasil (FOHB), no qual foi apontado que o setor hoteleiro planeja investir $\mathrm{R} \$ 12,8$ bilhões entre os anos de 2015 e 2020. Com isso, serão 630 novos empreendimentos, representando um crescimento de $65 \%$ no número de edificações hoteleiras. Já o número de apartamentos disponíveis passará de 94 mil para 164 mil, uma alta de 75\% no mesmo período (ABEOC, 2015). Mesmo sendo apenas previsões de investimentos, os números já denotavam interesse no desenvolvimento do setor.

O ramo hoteleiro visa geração de receita e lucro. Todavia, a hotelaria é muito afetada por influências externas. Pettrocchi (2002) exemplifica essas influências como os cenários socioeconômicos, as atuais mudanças em tecnologias e a disponibilidade de mão-de-obra, dentre outras. Outro fator externo que afeta a hotelaria é a competitividade do mercado, que também exige que os empreendimentos apresentem um diferencial em seus serviços para que possam ter mais lucratividade em seus negócios. Segundo Teboul (1991: 5), "quanto mais a concorrência é aberta, mais os clientes (ou seja, todos nós) podem tornar-se exigentes. [...] é necessário poder diferenciar o produto, propondo uma vantagem clara e indiscutível. Ora, a qualidade pode ser fonte desta diferença essencial." Desse modo, a busca por segmentos específicos no mercado hoteleiro se torna fator importante para o sucesso nos negócios.

Na visão de Paladini (2012a), uma abordagem básica para a definição de qualidade é o atendimento às necessidades, aos desejos, às expectativas e às preferências do consumidor. Miyazaki (2007) amplia mais o conceito e afirma que o atendimento às necessidades específicas do cliente inclui não só a qualidade inerente ao produto ou serviço desde a concepção e produção, mas a adequação da distribuição e oferta, espacial e temporalmente, garantindo a satisfação dos clientes finais. Essa satisfação é fruto do compartilhamento de objetivos e metas entre fornecedores e clientes envolvidos no processo.

Por sua vez, Castelli (2002) defende que o desempenho com qualidade das prestações hoteleiras é condição determinante para o sucesso empresarial, uma vez que são notórios uma concorrência empresarial acirrada e um cliente cada vez mais exigente. Para que os empreendimentos hoteleiros obtenham e ofereçam melhor nível em seus serviços, é necessário que algumas atividades principais sejam observadas e praticadas, entre elas o planejamento, o controle, a garantia e a melhoria da qualidade. Ainda segundo o autor, todo serviço é "resultado de um conjunto de ações que fazem com que o produto passe às mãos do consumidor. Através do serviço, pode-se vender tanto um bem material, quanto um bem imaterial" (Castelli, 2002:127). 
De acordo com Silva e Teixeira (2008: 174):

[...] faz-se necessário que empreendimentos hoteleiros estejam atentos às questões internas e externas, uma vez que mudanças no ambiente competitivo da hotelaria provocam alterações no nível de influência das forças ambientais sobre hotéis. As organizações lidam ainda com questões complexas, relacionadas à disponibilidade de recursos e com formação de alianças para obtenção ou ampliação de vantagens competitivas.

Uma forma de estar atento às mudanças do setor, como também uma possibilidade de fortalecimento através de alianças, apresenta-se nos contratos fechados com empresas aéreas para a hospedagem de tripulantes. Como o fluxo é permanente e a rotatividade alta, esse tipo de serviço prestado a empresas aéreas impacta diretamente na diminuição da sazonalidade dos hotéis parceiros.

Compondo parte do Setor Terciário de um país, a aviação está diretamente ligada ao setor de serviços. Dentre essas atividades, podem ser elencados os serviços de tripulantes e comissários, de manutenção e revisão de aeronaves e suas peças, de venda de passagens, de apoio aos passageiros e à carga nos aeroportos e em agências de passagens, de manutenção e atualização de serviços online, de administração e operação de aeroportos e de auxílio à navegação aérea.

A expressividade do setor aéreo é corroborada com números vultosos tanto para o mundo quanto para o Brasil. De acordo com o Air Transport Action Group (ATAG), "a indústria mundial do transporte aéreo proporciona mais de 58 milhões de empregos, transporta 3 bilhões de passageiros anuais e gera US\$ 2,4 trilhões do PIB global. Em paralelo, um terço de todo o comércio global em valor é transportado por via aérea [...]" (ABEAR2, 2014: 26). Enquanto que, em 2014, o Brasil transportou, através de empresas aéreas brasileiras e estrangeiras, cerca de "120 milhões de passageiros em voos domésticos e internacionais. Essas empresas levam anualmente no Brasil e entre o país e o exterior mais de 1,3 milhão de toneladas de carga [...]" (ABEAR, 2014: 27).

Em 2010, o número de viagens realizadas em aviões comerciais no mercado brasileiro atingiu o número de 50 milhões, representando um crescimento de $10 \%$ ao ano entre 2003 e 2008 (Mckinsey e Company, 2010). Quatro anos depois, o número subiu para 206 milhões de viagens dentro do Brasil, segundo informação do Ministério do Turismo (MTur) ${ }^{3}$.

Ciente da força comercial do setor da aviação, a Secretaria de Aviação Civil (SAC) divulgou o resultado de uma pesquisa ${ }^{4}$ que, entre outras conclusões, apontou para potencialidade na criação de novas rotas aéreas para o país. A pesquisa foi realizada com 150 mil passageiros em 65 aeroportos durante o ano de 2014. Entre as rotas mais desejadas, estavam os trechos: Rio de Janeiro (RJ) - Vila Velha (ES), Blumenau (SC) - São Paulo (SP), Campo Grande (MS) - Rio de Janeiro (RJ) (SAC: 2015).

Uma vez que o Brasil apresenta uma extensão continental, o transporte aéreo torna-se uma ferramenta essencial para o desenvolvimento e a integração nacional. De acordo com o MTur (2015), mais da metade das viagens de turismo, atualmente, dentro do território brasileiro, utiliza o avião como meio de transporte, com isso o aumento do fluxo aéreo é um agente claro de transformação do turismo interno. O turismo irrompe nessa hora como mola propulsora de desenvolvimento, aliando-se a outros componentes econômicos.

A competitividade do mercado de aviação no Brasil faz com que as empresas aéreas busquem novas estratégias para reduzir custos e atrair clientes. Segundo a ABEAR, a empresa pesquisada nesse trabalho conta hoje com um dos mais expressivos fatores de ocupação do mercado, demonstrando a assertividade em seu modelo de negócio, mostrando alto nível de crescimento entre 2012 e 2014, graças a uma estratégia claramente definida - excelência no atendimento e serviços aos clientes e valorização de seus colaboradores, entre eles o grupo de tripulantes que serviram como fonte para levantamento e análise qualitativa nesse trabalho. Isso porque como explica Neves (1993: 276), "o trabalho não pode ser compreendido apenas sob a ótica do processo gestionário, e a empresa não pode estar desvinculada da sociedade. Pensar uma política de qualidade nas empresas implica pensar na qualidade de vida de seus trabalhadores, no efetivo exercício de seus direitos trabalhistas, consolidando cada vez mais as instituições da sociedade para afirmação do processo democrático na sociedade brasileira”.

Visando atender cada vez melhor os passageiros, a empresa pesquisada foca também na satisfação interna de seus colaboradores através do reconhecimento e valorização profissional. Uma das estratégias é apresentar um grupo que trabalha diretamente com seus clientes, com bom nível de satisfação e contentamento com a empresa. Assim, a qualidade de serviços oferecida aos tripulantes durante os intervalos de descanso entre voos é essencial, pois ainda estão cumprindo suas jornadas de trabalho. 
Assim, abordando os temas hotelaria e qualidade em serviços, o presente estudo busca responder às seguintes questões norteadoras:

- Hotéis de capitais do nordeste do Brasil cumprem as normas de hospedagem estabelecidas pelos órgãos reguladores da aviação?

- Quais serviços hoteleiros diferenciados são oferecidos aos tripulantes?

- Esses hotéis apresentam qualidade nos serviços voltados aos tripulantes?

A partir da importância do segmento da aviação para a economia hoteleira no Brasil, as companhias aéreas se destacam como organizações corporativas cercadas de características próprias e ainda pouco exploradas pela literatura acadêmica brasileira. Diante do exposto, a justificativa da pesquisa repousou na importância do cumprimento das normas de hospedagem estabelecidas pelos órgãos reguladores da aviação, representando um dos fatores que pode influenciar a gestão da qualidade dos hotéis e, consequentemente, seu sucesso no atendimento a tripulantes. Desse modo, o estudo tornou-se relevante para mostrar como a hotelaria no nordeste do Brasil se apresenta e como pode melhorar o serviço oferecido aos tripulantes, consolidando parcerias com companhias aéreas e mostrando aos hotéis como oferecer serviço especializado a esse tipo de hóspede.

Estabeleceu-se como objetivo geral demonstrar o nível da qualidade nos serviços hoteleiros de capitais do nordeste do Brasil oferecidos a uma companhia aérea brasileira. Para tanto, buscou-se inicialmente levantar o cumprimento das normas de hospedagem estabelecidas pelos órgãos reguladores da aviação, apontar serviços diferenciados oferecidos por hotéis a tripulantes e descobrir o nível de satisfação com os serviços voltados à tripulação.

Dentre os procedimentos metodológicos, este estudo se respaldou em uma pesquisa bibliográfica e uma pesquisa documental para produzir o aporte do referencial teórico. Em seguida, foi necessária uma pesquisa de campo para produzir dados utilizados nas análises. Como instrumento para coleta de dados, foi elaborado um questionário respondido por tripulantes de uma companhia aérea brasileira ${ }^{5}$.

O presente trabalho também é classificado como uma pesquisa exploratória, de acordo com os objetivos, estabelecendo critérios e métodos para oferecer informações sobre o foco da problematização. Por sua vez, o método utilizado foi o indutivo, partindo de fatos particulares para uma conclusão genérica.

\section{Fundamentação teórica}

\subsection{A qualidade como ferramenta de competitividade na hotelaria}

O setor terciário, responsável pela oferta de serviços, está presente de variadas formas no cotidiano das pessoas, por exemplo, através da prestação de serviços bancários, de saúde, de educação e até mesmo com serviços de lazer, prestados por hotéis, restaurantes e locais de entretenimento. O setor de serviços, segundo o Governo Federal, foi o que mais abriu vagas de emprego em 2015. O Portal Mais Emprego, do Ministério do Trabalho e Emprego ofereceu, de janeiro a agosto de 2015, um total de 1.162.019 vagas espalhadas por todos os estados (Portal Brasil, 2015). Dessa forma, fica eminente que o mesmo é de extrema importância para o crescimento do país, alavancado pela demanda mandatória de mão de obra.

Segundo Carvalho et al (2013: 4), "hoje no Brasil e nos países desenvolvidos, existe uma tendência de a economia estar alicerçada no setor de serviços", que, por sua vez, é considerado fundamental tanto em termos sociais, através da geração de empregos, quanto em termos de estímulo à competitividade das organizações produtivas. Aliás, essa competitividade, também denominada de concorrência, fez cair por terra alguns mitos antigos no processo de prestação de serviços. Para Paladini (2012b), entre os mitos antigos estava a crença que serviços não se articulavam com tecnologia, com aporte de capital, com produção em grande escala, com estudo e pesquisa de mercado, com produção de riqueza e renda e com avaliação objetiva.

Para Serson (1999: 16), a definição de serviços é “o conquistar e manter clientes através de vantagens ou satisfações, geralmente com dominância intangível ou sendo proporcionadas em conexão com as vendas de bens tangíveis". Desse modo, é ressaltada a principal característica dos serviços, a intangibilidade, ou seja, o principal benefício oferecido ao cliente não é uma mercadoria física, mas todo o processo de oferecimento e usufruto do produto pelo cliente. Porém, esses serviços 'intangíveis' requerem qualidade igualmente ao setor de bens tangíveis (setor produtor de mercadoria física), pois tal qual esse último, os serviços são indicadores fortes na economia. 
A sociedade contemporânea e globalizada exigiu qualidade como sinônimo de diferenciação e, por esse motivo, Paladini (2012b: 35) é contundente ao declarar que:

[...] organizações produtoras de serviços tiveram que investir em tecnologia (para automatizar várias atividades, por exemplo); passaram a requerer aporte de capital (para investir em produtos diferenciados, por exemplo); foram forçadas a ampliar a escala do atendimento [...]. A prestação de serviços, assim, hoje se torna uma atividade que precisa ser bem concebida. Não há lugar para improvisos.

Hoje, várias empresas já reconhecem que a vantagem competitiva de mercado está intrinsicamente ligada à qualidade de seus serviços (Carvalho et al, 2013). Para que a qualidade possa ser percebida pelos clientes, algumas estratégias podem ser observadas e praticadas pelas empresas como a Gestão da Qualidade Total (GQT). Para que a qualidade possa ser percebida pelos clientes, algumas estratégias e ferramentas podem ser observadas e praticadas pelas empresas, inclusive pelas organizações hoteleiras. Devido à competitividade e a busca pela excelência no decorrer dos anos e da evolução tecnológica, muitas ferramentas foram criadas para ajudar nesse processo (Carvalho et al, 201). Muitas foram as ferramentas criadas pelos estudiosos de administração, entre elas, a matriz criada pela Boston Consulting Group (matriz BCG), o ciclo PDCA (do inglês, PLAN - DO -CHECK - ACT), o Balance Scorecard, assim como a Gestão da Qualidade Total (GQT)

Uma das ferramentas mais estudadas e citadas por vários autores é a Gestão da Qualidade Total (GQT). Um dos primeiros estudiosos a citar a GQT foi Feigenbaum, que em 1951 tornou-se conhecido por ser o pioneiro a discorrer sobre a qualidade sistêmica nas organizações e formular o Controle Total da Qualidade, abordo em seu livro Total Quality Control (Carvalho et al, 2013). No seu livro, Feigenbaum cita que:

A qualidade quem estabelece é o cliente e não os engenheiros, nem o pessoal de marketing ou a alta administração. A qualidade de um produto ou serviço pode ser definida como um conjunto total das características de marketing, engenharia, fabricação e manutenção do produto ou serviço que satisfazem às expectativas dos clientes" (Feigenbaum apud Maximiano, 2002).

Essa ferramenta administrativa fomenta a consciência de qualidade em todos os processos organizacionais, envolvendo inclusive distribuidores e demais parceiros de negócios. Sendo assim, a busca pela qualidade não deve estar associada apenas ao produto final; deve, na verdade, estar atrelada às atividades de cada uma das pessoas que compõem o sistema operacional de uma empresa, como também às atividades de parceiros exteriores. Desse modo, explanou-se sobre a importância da Qualidade Total para o setor (e para esse estudo), uma vez que essa ferramenta incentiva o conhecimento de todos os processos da organização e a busca pela excelência. Para Juran (2002: 15), "a gerência para a qualidade é feita utilizando-se os mesmos três processos gerenciais de planejamento, controle e melhoramento. Os nomes mudam para: planejamento da qualidade, controle da qualidade e melhoramento da qualidade".

Na concepção de Paladini (2012b), a GQT faz-se imprescindível no mundo contemporâneo porque busca gerar uma cultura, ou seja, um conjunto de valores que a sociedade atribui a determinados elementos, situações, crenças e ideias para dentro das organizações. Com isso, todos os elementos da empresa devem ser coordenados, de modo que esses elementos estejam sincronizados em um movimento organizado e direcionado, visando adequar o produto ao uso, tendo como base sua atividade no processo produtivo.

Castelli (2002) também reconhece a necessidade de padrões de qualidade para um melhor desempenho das empresas, sendo que estes padrões servem de base autoavaliativa. A busca por melhores padrões de qualidade faz com que as organizações elaborem produtos e ofereçam serviços eficazes, não apenas como um diferencial mas também como uma condição para a sua sobrevivência no mercado. $\mathrm{O}$ setor da hotelaria também está inserido nessa busca, não se diferenciando em nada dos outros setores do mercado.

Por sua vez, Carvalho, Abreu e Zago (2010: 13) direciona o processo de gestão de qualidade para a hotelaria estabelecendo que:

O hotel, como toda organização em que sejam implementados programas de qualidade, deve-se considerar aspectos importantes que gerem resultados positivos. Os pontos principais são o cliente, enfoque principal na mentalidade dos colaboradores, a definição de processo, método, sistema e a relação entre eles na produção de um bem ou serviço, visto que o hotel é um sistema, e que engloba toda a cadeia de processos deste, abrangendo as partes operacionais e administrativas, as quais servem de base para uma produção de serviços de excelência. 
O foco dos hotéis tem sido cada vez mais buscar a melhoria de seus produtos e serviços, conscientizando-se de que é a satisfação do cliente o mais importante, este que, por sua vez, está mais criterioso e exigente. Investir na qualidade de serviços é a forma mais acessível e eficiente de assegurar que as necessidades dos clientes sejam atendidas. A qualidade deve integrar o planejamento estratégico da empresa, passando a nortear suas ações. (Castelli, 2002)

As organizações hoteleiras devem compreender que a qualidade precisa também estar presente em fatores humanos. De acordo com Castelli (2002: 23), "a qualidade humana é crucial nas prestações hoteleiras. [...] Produtos e serviços com qualidade superior só podem provir de funcionários com alto nível de qualificação, inseridos num excelente processo." No ramo do turismo e da hospitalidade, o profissional qualificado e satisfeito produz resultados mais positivos junto ao seu público consumidor.

Para a hotelaria de hoje, os investimentos na qualidade de serviços não estão relacionados apenas às ações básicas de hospedagem mas também aos itens agregados a esse tipo de empreendimento, por exemplo, academias e salões de beleza instalados dentro dos hotéis, trazendo praticidade aos hóspedes. Paladini (2012a) define qualidade como sinônimo de inovação, de competência, persistência e, até mesmo, agressividade. $\mathrm{O}$ empenho em inovar e oferecer um serviço diferenciado ao hóspede faz com que esse se fidelize à empresa e ela possa se tornar mais competitiva no mercado.

A fidelização para que o hóspede volte a se hospedar no hotel parte do binômio: satisfação e preço (Corte, 2009). Essa satisfação está atrelada à qualidade da hospedagem em que alguns aspectos do produto devem ser observados para que o cliente retorne. Esses aspectos se referem normalmente "à localização, qual o tipo de produto aconselhável; qual seria o produto conveniente a partir da análise do mercado em função da procura; e quais as políticas de produtos que poderiam ser aplicadas" (Serson, 1999: 55)

O grau de relacionamento do hotel com os clientes determinará a excelência na qualidade da prestação de serviços, consequentemente, o grau de confiabilidade do hotel será corroborado, quando a própria clientela funcionará como meio de divulgação, através da propaganda boca-a-boca com amigos e parentes. O hotel poderá adotar a qualidade em seus serviços como ferramenta competitiva, na qual esta mostrará não apenas as metas que a empresa deve alcançar, mas o melhoramento contínuo de resultados.

\subsection{Serviço de hospedagem para tripulação de companhias aéreas}

O Governo Brasileiro sancionou a Lei $\mathrm{n}^{0}$ 7.183, em 05 de abril de 1984, regulando a profissão de aeronauta. A habilitação desse profissional se encontra vinculada ao Ministério da Aeronáutica. Aeronautas exercem atividade a bordo de aeronave civil nacional, mediante contrato de trabalho firmado. Quando um profissional dessa área estiver em aeronave estrangeira, mas com contrato de trabalho regido por leis brasileiras, também será considerado aeronauta para efeitos dessa lei. Por sua vez, todo aeronauta, na função específica a bordo de aeronave, é denominado tripulante.

Essa lei também assegura outras providências como regime de trabalho, remuneração, concessões e transferências. Para o presente artigo, serão exploradas as informações expostas no Capítulo II, onde são esclarecidas as informações sobre repouso, escala de serviço e jornada de trabalho, uma vez que essas disposições corroboradas pela lei garantem melhores condições de trabalho para a categoria dos aeronautas.

Na seção VI, do Capítulo II, os art. 32 e 33 abordam alguns itens importantes no que concerne aos períodos de repouso de tripulantes, como visto a seguir:

Art. 32 - Repouso é o espaço de tempo ininterrupto após uma jornada, em que o tripulante fica desobrigado da prestação de qualquer serviço.

Art. 33 - São assegurados ao tripulante, fora de sua base domiciliar, acomodações para seu repouso, transporte ou ressarcimento deste, entre o aeroporto e o local de repouso e vice-versa. (Lei $\mathrm{N}^{\circ} 7.183 / 84$ )

Após várias horas de voo, o repouso é essencial para os tripulantes, e o cumprimento da lei é condição sine qua non para a qualidade do mesmo. A jornada de trabalho exercida por esses profissionais é regulamentada na seção II, do Capítulo II, art. 20, sendo que é compreendida entre a hora da apresentação no local de trabalho e a hora em que o mesmo é encerrado. No art. 20, existem quatro parágrafos que delimitam detalhadamente quando deve começar e terminar a jornada de trabalho dos tripulantes:

$1^{\circ} \mathrm{A}$ jornada na base domiciliar será contada a partir da hora de apresentação do aeronauta no local de trabalho.

$2^{\circ}$ Fora da base domiciliar, a jornada será contada a partir da hora de apresentação do aeronauta no local estabelecido pelo empregador. 
$3^{\circ}$ Nas hipóteses previstas nos parágrafos anteriores, a apresentação no aeroporto não deverá ser inferior a 30 (trinta) minutos da hora prevista para o início do voo.

$4^{\circ}$ Ajornada será considerada encerrada 30 (trinta) minutos após a parada final dos motores. (Lei $\left.\mathrm{N}^{\circ} 7.183 / 84\right)$

Ainda no tocante à jornada de trabalho, a essa é estabelecida no art. 21, como sendo de 11 (onze) horas de duração do período de trabalho realizado por uma tripulação mínima ou simples. Esse tipo de tripulação é a utilizada em voos nacionais, tendo sua definição explícita nos artigos 10 e 11, da seção II, do Capítulo I:

Art. 10 Tripulação mínima é a determinada na forma da certificação de tipo de aeronave e a constante do seu manual de operação, homologada pelo órgão competente do Ministério da Aeronáutica, sendo permitida sua utilização em voos: locais de instrução, de experiência, de vistoria e de traslado.

Art. 11 Tripulação simples é a constituída basicamente de uma tripulação mínima acrescida, quando for o caso, dos tripulantes necessários à realização do voo. (Lei $\mathrm{N}^{\mathrm{o}} 7.183 / 84$ )

O número de tripulantes técnicos e de cabine ${ }^{6}$ é expressivo no Brasil. Segundo a ABEAR, em 31 de dezembro de 2014, as quatro maiores empresas aéreas do país contavam com 16.434 tripulantes, entre comandantes, copilotos e comissários. Devido ao número de profissionais dessa categoria e ao trabalho específico que eles exercem, há outros acordos que regulam a profissão além da Lei $\mathrm{n}^{\circ} 7.183$.

Em 2015, foi realizada a Convenção Coletiva de Trabalho da Aviação Regular, celebrada entre o Sindicato Nacional dos Aeronautas (SNA) e o Sindicato Nacional de Empresas Aeroviárias (SNEA). A Convenção buscou melhorar as condições de trabalho dos aeronautas, atendendo reivindicações que não estavam contempladas na lei reguladora da profissão. O SNA declara que os aeronautas beneficiados deviam operar em todo território nacional ou pertencer a empresas nacionais, ainda que baseados ${ }^{7}$ ou operando no exterior ${ }^{8}$. Encontram-se, no texto da Convenção, cláusulas econômicas, cláusulas sociais e cláusulas relativas à organização sindical.

Nas cláusulas econômicas, apresentadas no item número 2.3 da Convenção, são tratados valores referentes às diárias de alimentação fixadas em território nacional para as refeições principais: almoço, jantar ou ceia ${ }^{9}$. A diária de alimentação relativa ao café da manhã deve ser igual a $25 \%$ do valor determinado para as demais refeições, exceto se este já estiver incluído na conta do hotel (SNA, 2015).

Pertinente às cláusulas sociais, é assegurado ao tripulante mais um benefício no que se refere ao repouso, garantindo que o mesmo não precise ficar em uma unidade habitacional com outro tripulante. Esse benefício está definido no item 3.5.9, afirmando que qualquer aeronauta permanecerá em acomodações individuais quando pernoitando fora de sua base contratual a serviço. (SNA, 2015)

Também é definido o limite semanal de horas trabalhadas. Conforme o item 3.3.9, é definido que esse limite seja de 44 (quarenta e quatro) horas para todos os aeronautas. Superado o limite previsto nesta cláusula, haverá pagamento de hora excedente ou haverá compensação na forma de folga. (SNA, 2015)

Concernente à organização sindical, caso as empresas não cumpram qualquer cláusula da Convenção Coletiva do Trabalho, essas pagarão multa ao aeronauta prejudicado. Desse modo, o SNA coloca-se como um órgão atuante, preocupando-se com o bem-estar de seus membros. De modo geral, o que se observa é que empresas aéreas cumprem com as cláusulas acordadas, objetivando oferecer melhores condições de trabalho e descanso aos tripulantes.

\section{Procedimentos metodológicos}

Essa seção traz os componentes da trajetória da pesquisa. A importância do reconhecimento desses componentes deve-se ao fato deles servirem para levantamento, organização e mostra dos resultados dos problemas apontados.

Tratou-se aqui de uma pesquisa com delineamento teórico-empírico. Iniciou-se com um estudo exploratório do tema. Em seguida, apresentam-se características de um estudo descritivo, pois os objetivos propostos foram alcançados por meio da descrição e análise do nível de satisfação com os serviços hoteleiros específicos para tripulantes de uma companhia aérea e o cumprimento das normas de hospedagem estabelecidas pelos órgãos reguladores da aviação.

Utilizou-se o método indutivo, quando através de fatos particulares se extraiu uma conclusão genérica. Aqui, a indução ocorreu através do posicionamento de parte dos tripulantes de uma companhia aérea em relação aos serviços hoteleiros a eles prestados, extraindo-se uma conclusão ampla, representando a possível visão da maioria sobre o assunto. 
Quanto ao objeto, o trabalho foi bibliográfico, documental e de campo. A pesquisa bibliográfica foi realizada em livros e artigos científicos formando a base da revisão da literatura sobre turismo e gestão da qualidade. Segundo Oliveira (2007: 69), essa etapa é imprescindível para esse tipo de trabalho, pois "há a certeza que as fontes a serem pesquisadas já são reconhecidamente do domínio científico." Esse tipo de elemento encerra contribuições de vários autores e é considerada fonte secundária. Sobre a pesquisa documental, a mesma se deu através das leis vigentes sobre a regulamentação dos aeronautas e convenções sobre os direitos dos mesmos. Embora os objetos de investigação tenham sido fontes escritas como na pesquisa bibliográfica, aqui estão em outra categoria por não terem recebido tratamento analítico, sendo consideradas fontes primárias (Oliveira: 2007). Partindo para a pesquisa de campo, realizada no início de 2015 , foram levantados dados através de um questionário aplicado com 70 comissários de voo ativos de uma companhia aérea brasileira, de um total de 800 registrados em seu quadro de funcionários.

O questionário elaborado como instrumento da pesquisa apresentou oito perguntas semiabertas ou abertas e foi respondido de forma manual e presencial durante as horas de descanso entre voos. Aponta-se aqui que um dos pesquisadores trabalhava na referida empresa e foi o responsável pela aplicação de todos os questionários. Esse instrumento buscou avaliar os serviços hoteleiros voltados para o atendimento de tripulantes. O cenário da pesquisa foi caracterizado pelos hotéis parceiros da companhia aérea situados nas cidades de Fortaleza, Natal, João Pessoa, Aracajú, Maceió, Recife e Salvador.

Como análise dos dados obtidos foi utilizada a estatística descritiva que sintetiza valores semelhantes para um entendimento macro da variação desses valores. Na estatística descritiva, os dados são melhores organizados e descritos por meio de tabelas, gráficos e medidas descritivas. Porém, para o presente trabalho nenhuma tabela foi apresentada.

Dentre as limitações enfrentadas estiveram o tempo de realização da pesquisa e o número final de respondentes. Como primeiro fator, um dos pesquisadores precisava do trabalho finalizado para a obtenção do diploma de graduação, por isso todo o processo de elaboração de projeto até a apresentação final não ultrapassou 12 meses. Além disso, mesmo o universo da pesquisa de campo contando com 800 funcionários, o número de entrevistados para a amostra alcançou apenas 70 respondentes. Isso ocorreu porque não foram disponibilizados pela companhia aérea os correios eletrônicos dos funcionários e porque houve repetição nas equipes formadas pelos tripulantes, impossibilitando a aplicação do instrumento com pessoas já participantes.

\section{Resultados e discussões}

Apresentam-se aqui as análises e discussões acerca dos resultados obtidos com a pesquisa realizada entre agosto e novembro de 2015 , durante a qual 70 comissários de voo de uma única companhia aérea brasileira responderam a um questionário. Essa amostra foi constituída pela análise de comissários com idade entre 20 e 50 anos, dos gêneros masculino e feminino, e com amplo grau de escolaridade, tanto comissários com ensino médio, quanto comissários com pós-graduação. Considerando as especificidades de escalas individuais e as nove folgas mensais impostas por lei, os respondentes usam serviços de hospedagem entre 15 e 20 dias por mês.

A partir do levantamento dos dados, tem-se o direcionamento de todo o trabalho, que é compreender e analisar o nível de satisfação com os serviços hoteleiros específicos e o cumprimento das normas de hospedagem estabelecidas pelos órgãos reguladores da aviação brasileira.

Conforme a Convenção Coletiva de Trabalho da Aviação Regular de 2015, que exige que os tripulantes sejam hospedados em apartamentos individuais, todos os comissários questionados responderam que esse direito está sendo cumprido, e que estão se hospedando em apartamentos individuais em todas as capitais do Nordeste onde a empresa aérea opera, a saber, Fortaleza, Natal, João Pessoa, Recife, Maceió, Aracajú e Salvador. Já em conformidade com a Lei $n^{0} 7.183$, que garante aos tripulantes diárias para gastos complementares fora de sua base domiciliar, todos os comissários questionados também declararam que a empresa paga efetivamente essas diárias em todas as capitais do Nordeste, não sendo necessário que eles utilizem recursos próprios para posterior ressarcimento.

No âmbito relativo à qualidade, o grupo pesquisado foi questionado sobre a satisfação com os estabelecimentos elencados pela companhia como pontos de apoio de suas tripulações, incluindo-se os diversos setores e serviços do hotel. Sobre a qualidade dos hotéis (Gráfico 1), 34\% dos comissários responderam que estão satisfeitos com a qualidade de todos os hotéis, $63 \%$ estão satisfeitos apenas em algumas capitais e 3\% não estão satisfeitos com a qualidade de nenhum hotel. Entre os hotéis com 
qualidade satisfatória, as cidades mais citadas foram João Pessoa, Natal e Fortaleza. Conclui-se, assim, que quase a totalidade dos pesquisados aprova, ainda que parcialmente, a qualidade da hospedagem nos hotéis com que a empresa trabalha, pois, se for somado os percentuais dos dois grupos que apontaram satisfação, chega-se a $97 \%$ dos entrevistados. Acredita-se também que a pequena parcela não satisfeita pode ser conquistada, já que o número não é tão elevado, requerendo apenas mais atenção na qualidade dos serviços prestados pelos empreendimentos hoteleiros em questão.

\section{Gráfico 1: Satisfação com a qualidade dos hotéis em capitais do Nordeste do Brasil.}

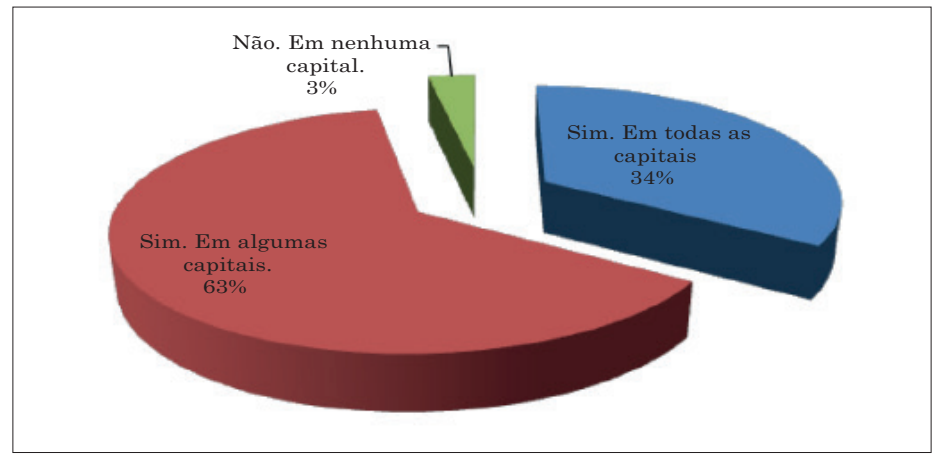

Fonte: Dados da pesquisa (2016).

No intento de descobrir qual setor do hotel tem diferencial na hospedagem dos tripulantes, esses foram questionados sobre qual setor é o mais importante durante sua estada (Gráfico 2). Na pesquisa, $64 \%$ dos pesquisados consideram a governança o setor mais importante, $23 \%$ o setor de alimentos e bebidas, $9 \%$ apontaram a recepção e $4 \%$ a lavanderia. Desse modo, a pesquisa revela que o setor de governança, responsável pela limpeza, organização e conservação tanto das áreas comuns, quanto dos apartamentos, torna-se crucial para a qualidade na hospedagem desse tipo de cliente. Pode-se também destacar que outros serviços ligados ao setor de governança também podem ser explorados de uma melhor forma para atender às necessidades desse tipo de cliente. Dentre esses setores, estão a rouparia e a lavanderia, que foi citada como essencial por $4 \%$ dos respondentes.

\section{Gráfico 2: Setor hoteleiro mais importante.}

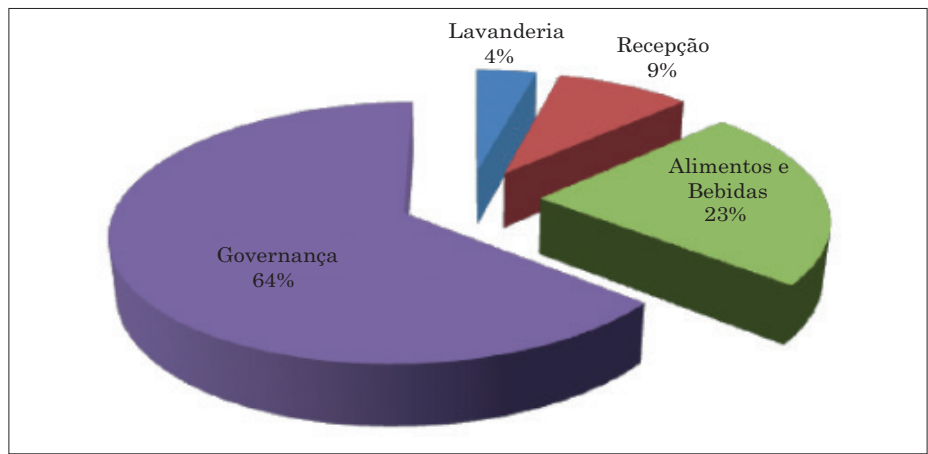

Fonte: Dados da pesquisa (2016).

Com o desígnio de especificar claramente e buscar o serviço mais relevante para o sucesso na qualidade do atendimento a esse grupo em estudo, no questionário foi abordado o serviço mais importante para qualidade na hospedagem (Gráfico 3). A partir desse questionamento, verificou-se que $81 \%$ consideram 
a limpeza do quarto, banheiro e áreas comuns como o serviço principal; outros $10 \%$ consideram boa conexão de Internet $w i$ - $f$ mais importante; $6 \%$ apontaram o atendimento dos recepcionistas; $1 \%$ requereu a existência de academia, piscina e sauna, outros $1 \%$ preferiu a existência de room service ${ }^{10} 24$ horas como serviço principal para a qualidade na hospedagem. Dentre os questionados nenhum relatou variedade de alimentos no café da manhã como diferencial para a hospedagem de tripulantes. Assim, fica corroborada a importância do setor de governança como agente principal para o êxito em qualquer empreendimento hoteleiro que busque atender ao público em estudo.

\section{Gráfico 3: Serviço hoteleiro mais importante.}

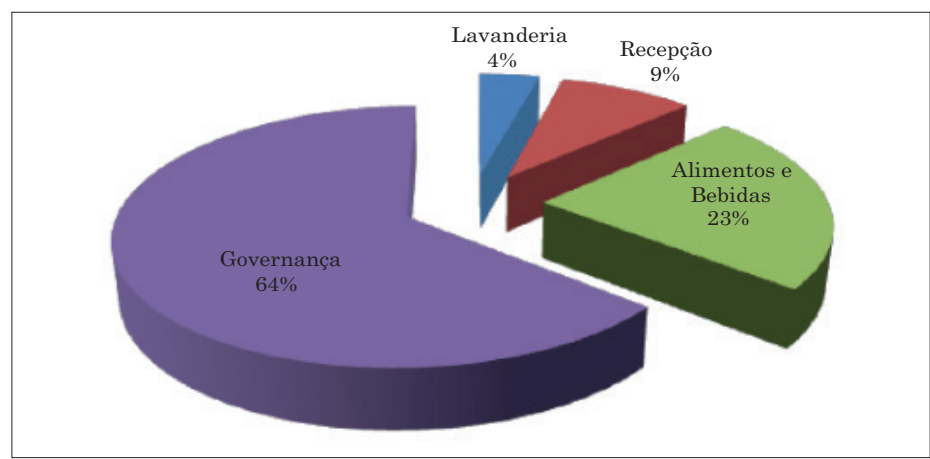

Fonte: Dados da pesquisa (2016).

Objetivando relatar algum diferencial oferecido aos tripulantes por parte de cada hotel, foi questionada a existência de algum serviço extra. Todos os respondentes afirmaram que os hotéis oferecem serviço de lavagem de uniformes como cortesia, bem como o fornecimento de água. Esse questionamento aponta para a possível conquista de um cliente para o hotel em outras circunstâncias que não a estada durante o trabalho. Isso ocorre porque principalmente o zelo com o cuidado do uniforme do tripulante, por parte da governança, expressa um cuidado relevante às necessidades do hóspede em questão.

Para conhecer mais algumas características e anseios desse tipo de cliente em estudo, os tripulantes foram indagados sobre a possibilidade de estada em algum dos hotéis utilizados durante a jornada de trabalho em uma viagem a lazer. $79 \%$ dos pesquisados afirmaram que se hospedariam em algum dos estabelecimentos. Foram considerados principalmente como fatores de anuência a localização, possíveis descontos nas diárias e o atendimento oferecido aos clientes, como demonstram os depoimentos de três tripulantes:

Porque para tripulantes têm a vantagem do desconto na diária e geralmente a localização é muito boa, sempre próximo às praias. (pesquisado $\mathrm{A}, 2015)$

Porque tem qualidade e muitos hotéis dão um desconto na estadia para tripulantes que estão a passeio. (pesquisado B, 2015)

Porque no geral são hotéis bons, com localização próxima de praias e lojas de conveniência. (pesquisado C, 2015)

Já os tripulantes que afirmaram não se hospedar quando não estivessem a trabalho ( $21 \%$ dos pesquisados) tiveram entre suas explicações o fato de já não ter suas necessidades atingidas enquanto tripulantes; por conseguinte, possivelmente não as teriam também como um hóspede a passeio. Entre as explicações para essa decisão, encontram-se:

Não há limpeza adequada dos quartos e demais dependências dos hotéis. (pesquisado D, 2015)

Internet ruim e serviço de quarto demorado como, por exemplo: manutenção e room service. (pesquisado $\mathrm{E}, 2015)$

Diante de tais colocações, observa-se que os hotéis ainda precisam melhorar seus serviços diante das necessidades existentes, envolvendo turistas convencionais e tripulação, visto que este segundo grupo é cliente potencial, podendo retornar enquanto tripulação ou a passeio. 


\section{Considerações finais}

A partir dos resultados desta pesquisa, pôde-se concluir que existe hoje uma minoria que não está satisfeita com a qualidade dos hotéis em que se hospeda e outra parcela que não está satisfeita por completo pontualmente em algumas capitais do nordeste do Brasil. Não obstante, essa análise aponta alternativas que podem definir metas e objetivos para as organizações que buscam a excelência na prestação de serviços ao público em questão. Assim sendo, o êxito do serviço prestado pelos hotéis a esse público está no cumprimento das normas reguladoras de hospedagem em que o grupo profissional está inserido, além de investimentos em um funcionamento satisfatório do setor de governança, resultando assim na satisfação do cliente, que é o pilar da Gestão da Qualidade Total.

O objetivo da pesquisa foi atingido com sucesso, pois o trabalho conseguiu demonstrar o nível da qualidade nos serviços dos hotéis com os quais uma companhia aérea brasileira possui parceria. $\mathrm{O}$ trabalho mostrou que a empresa está honrando com a acomodação individual e também com pagamento das diárias, cumprindo assim com as normas de hospedagem estabelecidas pelos órgãos reguladores da aviação. Os comissários de voo revelaram que estão satisfeitos com a qualidade dos hotéis, quais setores são mais importante para a boa qualidade dos serviços, quais serviços em específico são mais importantes durante a estada, serviços de "cortesia" e ainda que a maioria dos tripulantes pode utilizar os empreendimentos como ponto de apoio para estada durante viagens de lazer.

Sendo assim, mesmo com itens de melhorias declarados por alguns comissários, notou-se que a infraestrutura e os serviços prestados pelos hotéis utilizados pela companhia pesquisada apresentam reconhecidamente um bom nível de satisfação, tornando esse público coorporativo passível de utilização dos estabelecimentos hoteleiros como turistas regulares. Em relação aos objetivos específicos, estes também foram alcançados, visto o levantamento realizado acerca do cumprimento das normas de hospedagem estabelecidas pelos órgãos reguladores da aviação.

Sabe-se que o assunto explorado não se esgota apenas nesse estudo. A partir dessa pesquisa, emergem outros assuntos que podem ser abordados em trabalhos posteriores, como a importância do setor de governança para a Gestão da Qualidade Total em um empreendimento hoteleiro, o levantamento sobre os serviços hoteleiros oferecidos em outras regiões do Brasil, o envolvimento de outras companhias aéreas brasileiras e, até mesmo, a comparação de distintos segmentos de clientes. Estudos nessa área buscam sempre a melhoria de um dos setores de maior destaque da economia mundial que é o Turismo e a Hotelaria.

\section{Bibliografia}

ABEOC - Associação Brasileira de Empresas de Eventos.

2015. Setor hoteleiro planeja investir $\mathrm{R} \$ 12,8$ bilhões no Brasil até 2020, aponta Fohb. Disponível em: $<$ http://www.abeoc.org.br/2015/03/setor-hoteleiro-planeja-investir-r-128-bilhoes-no-brasil-ate-2020-aponta-fohb/>. Acesso em: 14/11/16.

Bosisio, A. (coord.)

2005. Breve História do Turismo e da Hotelaria. Rio de Janeiro: Confederação Nacional do Comércio/ Conselho de Turismo.

BRASIL. Agência Nacional de Aviação Civil.

1984. Lei $N^{\circ} 7.183$, de 05 de abril de 1984. Regula o exercício da Profissão de Aeronauta, e dá outras providências. Disponível em: <http://www2.anac.gov.br/biblioteca/leis/lei7183\%20.pdf>. Acesso em 10/11/2015.

BRASIL. Associação Brasileira de Empresas Aéreas.

2014. Panorama 2014: setor aéreo em dados e análises. Disponível em: <http://www.abear.com.br/ uploads/arquivos/dados_e_fatos_arquivos_ptbr/ABEAR_Panorama2014_24jul_v2_simples.pdf>. Acesso em 11/11/2015.

BRASIL. Ministério do Turismo.

2015. Brasil tem potencial para 252 novas rotas aéreas, revela estudo. Disponível em: <http://www. turismo.gov.br/\%C3\%BAltimas-not\%C3\%ADcias/5608-brasil-tem-potencial-para-252-novas-rotas-a\%C3\%A9reas,-revela-estudo.html>. Acesso em 29/11/2015.

BRASIL. Portal Brasil.

2015. Portal Mais Emprego ofereceu mais de 1,1 milhão de vagas em 2015. Disponível em: <http:// www.brasil.gov.br/economia-e-emprego/2015/08/portal-mais-emprego-ofereceu-mais-de-1-1-milhao-de-vagas-em-2015>. Acesso em: 24/02/2016. 
BRASIL. Secretaria de Aviação Civil.

2015. Pesquisa revela perfil de passageiros, aeroportos e rotas no Brasil. Disponível em: <http://www. aviacao.gov.br/noticias/2015/10/pesquisa-da-secretaria-de-aviacao-revela-perfil-de-passageiros-aeroportos-e-rotas-no-brasil>. Acesso em: 11/11/ 2015.

BRASIL. Sindicato Nacional dos Aeronautas (SNA).

2015. Convenção Coletiva de Trabalho da Aviação Regular 2015/2016. Disponível em: < http://www. aeronautas.org.br/images/_sna/documentos/CCT_Regular_2015-2016.pdf>.Acesso em: 22/11/2016.

Carvalho, L. B; Abreu, L. F; Zago, C. A.

2010. Qualidade em serviços hoteleiros: o caso do Hotel LB-Manaus. Disponível em: <http://www.abepro. org.br/biblioteca/enegep2010_TN_STO_114_751_17518.pdf>. Acesso em 26/11/2016.

Carvalho, M. M. de. et al. (Org.).

2013. Gestão de Serviços: casos brasileiros. São Paulo: Atlas.

Castelli, G.

2002. Excelência em Hotelaria: uma abordagem prática. $4^{\text {a }}$ ed. Rio de Janeiro: Qualitymark.

Corte, M. R de.

2009. A qualidade dos serviços hoteleiros na ilha do Porto Santo. Disponível em: <https://www.repository. utl.pt/bitstream/10400.5/1434/1/TFM\%20Romana\%20Corte.pdf>. Acesso em 10/08/2015.

Freitas, E. L. de, Silva, J. S. S. e.

2011. "Estudo sobre a atuação dos órgãos de defesa do consumidor no setor hoteleiro." Em Mota, K. C. N, Aragão, A. R. F. (Org.) Educação tecnológica: teoria e prática do turismo, da hospitalidade e do lazer. Fortaleza, Expressão gráfica e editora: 92-118.

Juran, J. M.

2002. A qualidade desde o projeto: novos passos para o planejamento da qualidade em produtos e serviços.

São Paulo: Pioneira Thimsom Learning.

Maximiano, A. C. A.

2002. Teoria geral da administração: da revolução urbana à revolução digital. 3ed. São Paulo: Atlas.

Miyazaki, S. L.

2007. Certificação da Qualidade e Meio Ambiente: Projeto Formare. São Paulo: Veris Educacional.

Mckinsey \& Company.

2010. Estudo do Setor de Transporte Aéreo do Brasil: Relatório Consolidado. Disponível em: <http:// www.bndes.gov.br/SiteBNDES/export/sites/default/bndes_pt/Galerias/Arquivos/empresa/pesquisa/ chamada3/sumario_executivo.pdf $>$. Acesso em 10/08/2015.

Neves, M. A.

1993. Modernização industrial no Brasil: o surgimento de novos paradigmas na organização do trabalho. Educação \& Sociedade, n. 45, ago.

Oliveira, M. M.

2007. Como fazer pesquisa qualitativa. Petrópolis, Vozes.

Organização Mundial do Turismo.

2014. Panorama OMT del turismo internacional. Disponível em: <http://www.dadosefatos.turismo. gov.br/export/sites/default/dadosefatos/estatisticas_indicadores/downloads_estatisticas/OMT_Turismo_highlights_2014_sp.pdf>. Acesso em 19/09/2015.

Paladini, E. P.

2012a. Gestão da Qualidade: Teoria e Prática. 3. ed. São Paulo: Editora Atlas.

Paladini, E. P.

2012b. "Perspectiva Estratégica de Qualidade." Em Carvalho, M. M; Paladini, E. P (Org). Gestão da Qualidade: teoria e casos. Rio de Janeiro: Elsevier: ABEPRO: 25-85.

Petrocchi, M.

2002. Hotelaria: planejamento e gestão. São Paulo: Futura.

Serson, F.

1999. Hotelaria: a busca da excelência. São Paulo: Marcos Cobra.

Silva, A. L. e Miyashiro, R.

2007. Turismo e hospitalidade no Brasil: um estudo sobre os trabalhadores da hotelaria. São Paulo: CUT. Silva, A. J. H e Teixeira, R. M.

2008. Em busca de uma abordagem integradora para analisar vantagem competitiva no setor hoteleiro.

Revista Brasileira de Gestão e Desenvolvimento Regional, 4 (4): 172-192. Taubaté, SP.

Teboul, J.

1991. Gerenciando a dinâmica da qualidade. Rio de Janeiro: Ed. Qualitymark, Fundação Dom Cabral. 


\section{Notas}

1 Pero Vaz de Caminha escreve uma carta ao Rei de Portugal, Dom Manuel, e relata o primeiro episódio de hospedagem no Brasil. (Bosisio, 2005)

2 Sigla para Associação Brasileira de Empresas Aéreas.

3 Reportagem intitulada "Brasil tem potencial para 252 novas rotas aéreas, revela estudo".

4 Pesquisa realizada pela SAC e intitulada "O Brasil que voa - perfil dos passageiros, aeroportos e rotas do Brasil".

5 A companhia pesquisada forneceu autorização apenas para a pesquisa com seus colaboradores; proibindo a divulgação de nome, logomarca ou qualquer item que fosse de fácil identificação da mesma. Sendo assim, quando necessário, a empresa será citada no trabalho como companhia aérea $A$. (Nota dos autores)

6 Tripulação técnica é formada por piloto e copiloto, que têm conhecimentos e são habilitados para pilotar uma aeronave. Já a tripulação de cabine é formada por comissários de voo, responsáveis pelo gerenciamento da cabine de passageiros. (Nota dos autores)

7 Base é o local de apresentação do tripulante para o início e término do trabalho, onde iniciam e terminam os voos. (Nota dos autores)

8 Tripulantes das empresas de taxi aéreo e de empresas de aviação agrícola ficam suprimidos desse benefício, obedecendo à conceituação da profissão, conforme o disposto na Lei $n^{0} 7.183 / 84$. (SNA)

9 Para efeitos de pagamentos, o café da manhã está compreendido entre $05 \mathrm{~h} 00 \mathrm{~min}$ às $08 \mathrm{~h} 00 \mathrm{~min}$; o almoço entre às $11 \mathrm{~h} 00 \mathrm{~min}$ e às $13 \mathrm{~h} 00 \mathrm{~min}$ horas; o jantar entre às $19 \mathrm{~h} 00 \mathrm{~min}$ e às $20 \mathrm{~h} 00 \mathrm{~min}$; e a ceia, entre $00 \mathrm{~h} 00 \mathrm{~min}$ e $01 \mathrm{~h} 00 \mathrm{~min}$ (SNA).

10 Room service é a expressão em inglês para "serviço de quarto". Sendo assim, o room service acontece quando um hóspede tem um pedido atendido e entregue em seu apartamento, sem a necessidade de deslocamento do mesmo. Alguns hotéis normalmente disponibilizam esse serviço, também conhecido como "guest service", para a entrega de alimentação, itens de higiene, serviço de lavanderia, entre outros. (Nota dos autores) 